\title{
BMJ Open Serious game to promote socioemotional learning and mental health (emoTIC): a study protocol for randomised controlled trial
}

\author{
Usue De la Barrera, ${ }^{1}$ Silvia Postigo-Zegarra, ${ }^{2}$ Estefanía Mónaco, ${ }^{1}$ \\ José-Antonio Gil-Gómez, ${ }^{3}$ Inmaculada Montoya-Castilla (iD ${ }^{1}$
}

To cite: De la Barrera U, Postigo-Zegarra S, Mónaco E, et al. Serious game to promote socioemotional learning and mental health (emoTIC): a study protocol for randomised controlled trial. BMJ Open 2021;11:e052491. doi:10.1136/ bmjopen-2021-052491

- Prepublication history for this paper is available online. To view these files, please visit the journal online (http://dx.doi. org/10.1136/bmjopen-2021052491).

Received 16 April 2021 Accepted 17 November 2021

Check for updates

(c) Author(s) (or their employer(s)) 2021. Re-use permitted under CC BY-NC. No commercial re-use. See rights and permissions. Published by BMJ.

${ }^{1}$ Personalidad, Evaluación y Tratamientos Psicológicos, Facultad de Psicología y Logopedia, Universitat de València, Valencia, Spain 2Departamento de Psicología, Facultad de Ciencias de la Salud, Universidad Europea de Valencia, Valencia, Spain ${ }^{3}$ Instituto Universitario de Investigación en Automática e Informática Industrial, Universitat Politècnica de València, Valencia, Spain

Correspondence to Dr Inmaculada Montoya-Castilla; inmaculada.montoya@uv.es

\section{ABSTRACT}

Introduction The development of emotional competences may be a protective factor for mental health problems, promoting well-being at such a complex age as adolescence. Technologies may be used to carry out this empowerment because adolescents are attracted to them. The purpose of the study is to design a serious game based on the Mayer et a/s emotional intelligence ability model and analyse the effectiveness of the emoTIC programme to develop emotional competences, wellbeing, mental health, and personal strengths immediately after completion and at 12 months.

Methods and analysis The new version of emoTIC will be designed following the suggestions of the adolescents who participated in the pilot study and the results obtained from the statistical analysis. The participants will be 385 adolescents aged 11-16 years who will be randomly assigned to the control group and the experimental group. The experimental group will complete the emoTIC programme. The primary outcomes include emotional competences and subjective well-being. The secondary outcomes are self-esteem; general selfefficacy; personality; social and personal responsibility; school social climate; somatic complaints; depression, anxiety and stress symptoms; emotional and behavioural difficulties; suicidal behaviour; and subjective happiness. Data will be collected at three moments: baseline (T1), immediately post-intervention (T2) and 12-month followup (T3). The effectiveness of the programme will be analysed using different statistical packages.

Ethics and dissemination The study has been approved by the Ethics Commission of the University of Valencia (H152865096049), and the standards of the Declaration of Helsinki to collect the data will be followed. Results will be disseminated across the scientific community.

Trial registration number ClinicalTrials.gov Registry (NCT04414449).

Trial sponsor University of Valencia. Principal investigator: Inmaculada Montoya-Castilla.

\section{INTRODUCTION}

According to the World Health Organization (WHO), over 17 million adolescents, between 10 and 19 years, experience mental health problems such as depression, anxiety
Strengths and limitations of this study

- A strength of this project is to provide a serious game to promote emotional competences and wellbeing adapted to the needs of adolescents.

- The emoTIC programme will be available from any device (e.g., laptops, smartphones, tablets or computers) making it accessible to the majority of adolescents.

- The emoTIC programme is based on a solid theoretical model previously used in other programmes for the development of emotional competences which have shown positive outcomes.

- Family is not included in the intervention, which can be seen as a limitation of the programme.

or behavioural disorders ${ }^{1}$; and suicide is the second leading cause of death among young people worldwide. ${ }^{23}$ Thus, a high number of adolescents suffer from emotional problems and will need pharmacological or psychological treatment. This is a public health problem whose prevention and treatment should be considered a priority.

The role of emotional intelligence

Intervening in emotions during adolescence is essential because it is a turning point in life with the development of new psychosocial and cognitive possibilities that have a neurobiological substrate. ${ }^{4}$ An adequate emotional development at this age would contribute to subjective well-being, fostering adjustment and preventing externalising and internalising problems, ${ }^{56}$ as well as improving social relationships in different contexts (peers, family, school, etc.). ${ }^{78}$ Emotional intelligence is a buffer against the negative effects of stress ${ }^{9}$ and it is considered a protective factor for suicidal behaviour. ${ }^{10}$

Empirical evidence suggests that emotional education programmes are effective and may 
provide several benefits to adolescents. ${ }^{11}$ For example, adolescents increased their intrapersonal and interpersonal emotional intelligence, and improve their stress management and general mood with a programme based on Bar-On's model ${ }^{12}$; and emotional programmes based on Mayer and Salovey's model improved adolescents' ability to perceive and manage emotions and satisfaction with life, while cyberaggression was reduced. ${ }^{8}$ Therefore, a web-based application such as emoTIC, which permits to follow a full intervention promoting emotional competences, may help to enhance adolescents' mental health.

\section{The role of technology}

One of the fundamental challenges with adolescents is to get them involved in the therapeutic process and motivated to carry out prevention and intervention programmes. ${ }^{13}$ Promoting learning and well-being through technologies could improve the motivation of adolescents to engage in socioemotional programmes. ${ }^{14}$ The use of digital interventions for promoting mental health and preventing mood disorders in adolescents has promising results. ${ }^{1}$ In addition to technology, games can facilitate learning and promote motivation. ${ }^{15}$ In recent years, digital educational interventions have been implemented to prevent suicide ${ }^{16}$ or decrease depression and anxiety, ${ }^{17}$ but fewer focus on the development of emotional competences. Among the programmes designed to promote emotional competences, the following may be highlighted: the MoodGYM programme ${ }^{18}$ was designed to prevent symptoms of anxiety and depression in adolescents (12-17years); the Think, Feel, Do programme ${ }^{19}$ was developed to improve mental health and prevent emotional and behavioural problems in healthy adolescents (10-12years) and adolescents with emotional health problems (moderate anxiety or low mood) (10-16years); the Bite Back programme ${ }^{20}$ was designed to improve adolescent well-being and mental health (12-18years); the CopeSmart programme ${ }^{2122}$ was focused on developing mental health through emotional self-monitoring and the promotion of positive coping strategies (15-18years); the video game $\mathrm{Happy}^{23}$ was designed to train emotional competences in situations both in everyday life and peer conflict at school, as well as to recognise and regulate emotions and learn adaptive and assertive responses (8-16years); the multimedia programme Developing Emotional Intelligence $e^{24}$ and the video game Spock ${ }^{6}$ were focused on developing the four Mayer and Salovey's competences of emotional intelligence in adolescents (8-14years and 17-18years, respectively); the video game Aislados $^{25}$ was designed to improve the social competence and socioemotional well-being in adolescence (12-17 years); finally, the online video game REThink is one of the most rigorously investigated video games aimed to promote emotional resilience, prevent mental health and develop emotional skills. ${ }^{26-29}$ REThink is based on positive preventive programmes derived from rational emotive behavioural therapy and education, and it is addressed to adolescents aged 10-16years. This kind of programmes showed effectiveness to promote emotional competences and mental health. However, to our knowledge, there are few serious games focused on emotional competences based on Mayer and Salovey's model and other related variables implemented through mobile devices that have proven their effectiveness in healthy Spanish adolescents aged 11-16years, neither rigorously tested using a sample equally distributed by gender and a control group.

\section{The current study}

The development of emotional competences may be a protective factor for mental health problems, promoting adolescents' well-being. Technologies may be used in a positive way to carry out this empowerment because adolescents are used and attracted to them. Thus, the aims of the research are to design a serious game intended to prevent mental health problems and promote wellbeing in healthy Spanish adolescents between 11 and 16 years old; and to analyse its effectiveness to develop emotional competences and personal strengths immediately after completion of the programme and up to 12 months. The study hypotheses are: (1) adolescents in the emotional ability programme will show an improvement in emotional competences, personal strengths and well-being, and less mental health difficulties than adolescents in the control group; and (2) improvements will be maintained up to 12 months.

\section{METHODS AND ANALYSIS}

Following the Standard Protocol Items: Recommendations for Interventional Trials statement, ${ }^{30}$ the current study protocol describes the details of the study rationale, proposed methods, organisation and ethical considerations.

\section{Study design and setting}

A pilot study with a preliminary version of emoTIC was carried out in 2019, showing benefits in adolescents' self-esteem, hedonic balance and emotional symptoms. ${ }^{31}$ Participants informed that they have learnt emotional competences, social skills, and personal strengths; and suggested modifications to the duration, content, game mechanics, and design of the programme. ${ }^{32}$ These suggestions were incorporated into this new version of emoTIC. On the technical side, the programme has been transformed into a self-applicable tool and the graphics have been refined. On the content side, competences such as stress coping strategies, assertiveness or self-efficacy were added. This protocol describes an interventional quasiexperimental study, randomised clinical trial.

\section{Participant timeline}

The overall study was initiated in 2018 and the design of the platform was carried out during that year. In 2019, participants were recruited for a pilot study in order to test the platform and improve the programme. The main study is planned to take place from January 2021 until 
Table 1 Time schedule for the study

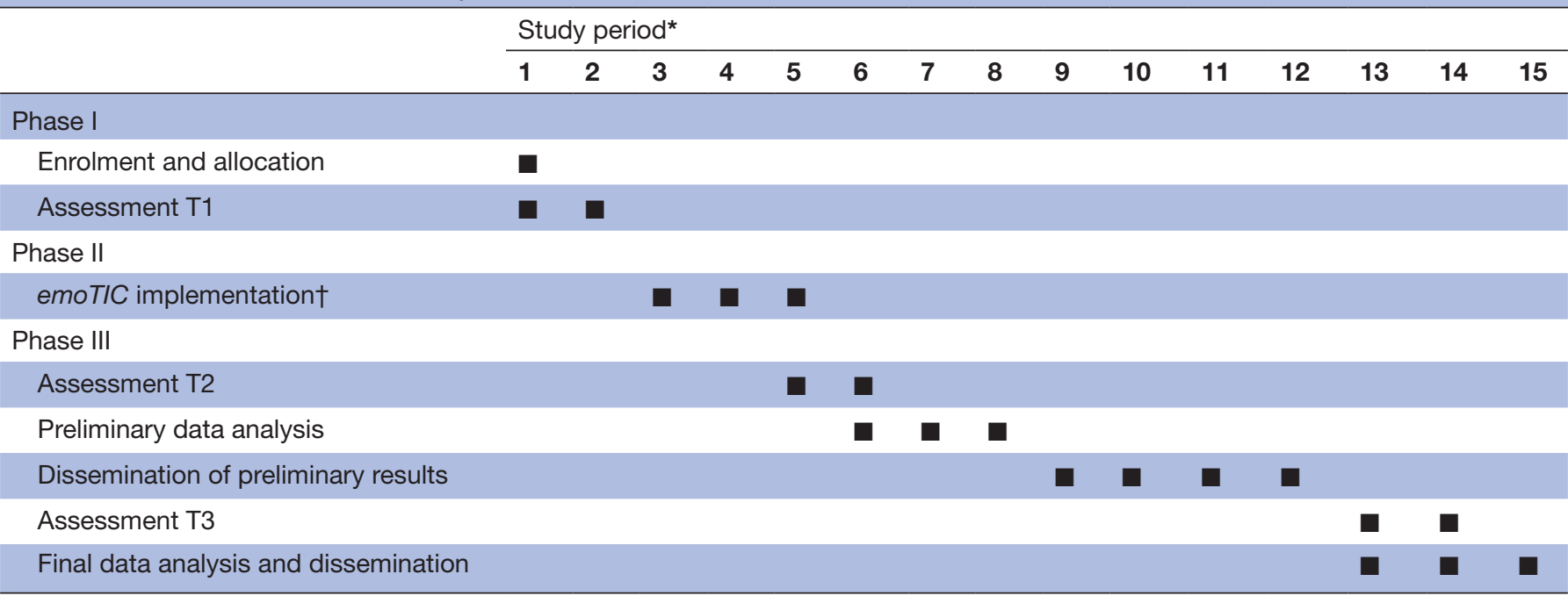

T1=baseline; T2=post-treatment; T3=follow up.

*Presented in months.

†Only experimental group will complete emoTIC programme.

March 2022 (table 1). The main objectives of the phase I are the selection of targeted high schools, the request for informed consent and the initial assessment. Contact will be first with high school principals who have already manifested their interest and then will be extended to other centres in Spain. After the meetings with the principals, we will request informed consent from the families and adolescents who will participate in the programme. Prior to the implementation, adolescents will be requested to complete a battery of questionnaires. The main objective of the phase II is the implementation of the programme. Students will access the programme's website (www.emoticspace.com) and fulfil the activities of the programme in a maximum period of 3 months. Tutors will be involved to motivate the adolescents, as well as to monitor their progress. The main objective of the phase III is to analyse the effectiveness of the emoTIC programme. Once it has been completed, the variables assessed before the implementation will be reassessed. Also, a follow-up assessment will be carried out up to 12 months later. The principal investigator will make the final decision to terminate the trial.

\section{Participants and eligibility criteria}

Participants will be recruited from Spanish high schools. To participate in the project, adolescents between 11 and 16 years old will be requested to voluntarily accept to participate in the study. They and their legal guardians will have to sign the informed consent for participation (inclusion criteria). Exclusion criteria will be having a high rate of school absenteeism, not understanding the Spanish language and a diagnosis of psychological disorder.

\section{Patient and public involvement}

Participants were involved in the design of the research in the pilot study. Adolescents provided suggestions to improve the final version of the programme.

\section{Interventions}

The emoTIC programme aims to promote the four emotional competences of the emotional intelligence model of Mayer and Salovey. ${ }^{33}$ In addition, other competences and strengths proposed by Collaborative for Academic, Social, and Emotional Learning ${ }^{35}$ are considered, intending to promote intrapersonal abilities (selfawareness and self-management), as well as interpersonal (social awareness and relationship skills) and cognitive (responsible decision-making) competences. The emoTIC programme consists of four modules, each one including eight activities and taking place in a different area of a planet called $E-M O O D$, following four general objectives: (1) emotional perception, valuing emotions and opening to the emotional world; (2) facilitation and emotional understanding; (3) stress management and conflict resolution; and (4) emotional regulation and self-motivation (table 2). The programme is available on a web-based platform that can be accessed from any device (e.g., laptops, smartphones, tablets or computers, among others). The mechanics of emoTIC as a serious game is a space adventure. The player has crashed on $E-M O O D$ planet and the main objective of the game is to return to Earth, for which the player will have to obtain pieces to build a spaceship, as well as oxygen, fuel and crew members. The advance in the programme offers a positive reinforcement by obtaining the resources needed to return to Earth every time the player successfully passes an activity and moves to a new zone of the planet, as well as gaining points that can be exchanged for: (a) access to play minigames specifically designed with the same atmosphere as emoTIC 
Table 2 Activity contents and emotional competences

\section{A Activity content}

1.1 The main characters of the planet ask adolescents to define emotions and test their emotional intelligence through a quiz.

1.2 The characters explain the emotion's dimensions and the user is asked to indicate the levels of intensity and liking of the emotions they are experiencing at the moment.

1.3 Human faces with different facial expressions are provided by the main characters and the adolescents are asked to identify the facial expressions corresponding to each emotion.

1.4 The black stripes covering the faces gradually disappear and the adolescents are asked to identify the emotion as soon as possible.

1.5 The adolescents focus on their feelings at that moment through a platform-guided audio. They are asked to draw and label their emotions.

1.6 The main characters provide drawn panels that represent emotional situations. The adolescents are asked to identify which emotion each person is feeling depending on the situation.

1.7 Three people speak in different languages and the adolescents are asked to identify the emotions they

1.8 The main characters give clues to the adolescents to guess the hidden emotion. They offer information

\section{Competences}

Basic concepts of emotions about valence, arousal, physical experience, similar emotions and situations in which the emotion is usually felt.

2.1 The main characters propose a quiz to understand the function and meaning of emotions. Then, they provide situations to the adolescents and they are asked to identify how the emotion may help in each situation.

2.2 The characters encourage the adolescents to classify different emotions by categories: love, joy, sadness, fear, etc.

2.3 An emotional situation is presented. The adolescents may try to understand how the person feels based on the thoughts that the situation generates in the characters.

2.4 The adolescents indicate their perception of the arousal and hedonic valence levels in complex emotions.

The main characters provide feedback and a definition of each emotion.

- Perceiving emotions*

- Self-awareness $\dagger$

Perceiving emotions*

Perceiving emotions*

Perceiving emotions*

Self-awareness ${ }^{-}$

- Perceiving emotions*

Self-awareness $\dagger$

Perceiving emotions*

Self-awarenesst

Perceiving emotions*

Facilitating thought using emotions*

- Understanding emotions*

- Understanding emotions*

Facilitating thought using emotions $^{\star}$

- Understanding emotions ${ }^{*}$

- Self-awareness $\dagger$

2.5 The adolescents can discover the meaning of moral emotions with the help of the main characters.

\subsection{The adolescents analyse a variety of emotional situations, trying to understand feelings and propose the 'intelligent optimist' thought. The main characters provide feedback to their performance.}

2.7 The adolescents reflect on their strengths and try to solve an emotional problem. The main characters provide information about each strength to help adolescents become aware of how to use them.

2.8 The main characters offer the adolescents their method for analysing emotional situations and they are asked to put it into practice.

\subsection{The main characters ask the adolescents to indicate on their own bodies where they feel tension when they are stressed. They then explain the phases of stress and the adolescents are asked to classify different stressful situations. \\ 3.2 The main characters present different sounds (busy streets, sounds of nature...) and the adolescents are asked to determine whether they find them stressful or calming.}

3.3 The main characters teach the users strategies for coping with stress. Then, the characters describe their own stressful situations and the adolescents are asked to help them cope with those situations.

3.4 The main characters explain and practise three relaxation techniques with the adolescents.
3.5 The adolescents find themselves in a labyrinth and in order to escape, they are asked to confront alien characters, who express various emotions, and respond appropriately.
3.6 The main characters show the users several galactic portals with texts depicting social situations. Adolescents are asked to decide whether or not the behaviour depicted is respectful.
Social awareness $†$
- Social awareness $\dagger$

Facilitating thought using emotions ${ }^{*}$

- Understanding emotions*

- Facilitating thought using emotions*

- Self-awareness†

- Self-awarenesst

- Self-management $\dagger$

Facilitating thought using emotions*

- Understanding emotions

- Self-management $†$

- Responsible decision-making $†$

- Psychoeducation about stress

Identifying and classifying stressors

- Identifying stressful situations that impact on mood

Stress coping strategies

- Self-management $†$

Stress coping strategies

- Relaxation techniques

Self-management $†$ 


\section{Table 2 Continued}

\begin{tabular}{|c|c|c|}
\hline A & Activity content & Competences \\
\hline 3.7 & $\begin{array}{l}\text { The adolescents are asked to identify people's emotions by taking into account their thoughts and } \\
\text { interpretation of the situation. The main characters provide feedback. }\end{array}$ & $\begin{array}{l}\text { Facilitating thought using } \\
\text { emotions* } \\
\text { Social awareness } † \\
\text { Relationship skills } †\end{array}$ \\
\hline 3.8 & The main characters explain what assertiveness is and how adolescents may use it in social situations. & - Relationship skills $\dagger$ \\
\hline 4.1 & $\begin{array}{l}\text { The adolescents use a traffic light to indicate their agreement or disagreement with affirmations about } \\
\text { emotional regulation. The main characters provide feedback. }\end{array}$ & $\begin{array}{l}\text { Managing emotions* } \\
\text { Self-management } †\end{array}$ \\
\hline 4.3 & $\begin{array}{l}\text { The main characters ask the adolescents to imagine a difficult emotional situation and they are asked } \\
\text { to label the emotion, think about the emotional regulation strategies they used and determine their } \\
\text { usefulness. }\end{array}$ & $\begin{array}{l}\text { Managing emotions* } \\
\text { Responsible } \\
\text { decision-makingt }\end{array}$ \\
\hline 4.5 & $\begin{array}{l}\text { The main characters challenge adolescents with conflicting situations to reflect on values and } \\
\text { decision-making. }\end{array}$ & > Self-awareness $\dagger$ \\
\hline 4.6 & $\begin{array}{l}\text { The adolescents make a recipe for happiness with five ingredients. Aliens ask them to whittle them } \\
\text { down to just one. }\end{array}$ & $\begin{array}{l}\text { Managing emotions* } \\
\text { Self-management } †\end{array}$ \\
\hline 4.7 & $\begin{array}{l}\text { The main characters take a journey around the planet with the adolescents to reflect on what they } \\
\text { have learnt from the challenges. }\end{array}$ & $\begin{array}{l}\text { Self-awareness } \dagger \\
\text { Self-management } \dagger\end{array}$ \\
\hline 4.8 & $\begin{array}{l}\text { The main characters confront the adolescents with challenges about their future and the goals they } \\
\text { want to achieve. The adolescents are asked to reflect on the challenges and goals according to what } \\
\text { they have learnt. }\end{array}$ & $\begin{array}{l}\text { Self-awareness } \dagger \\
\text { Self-management } † \\
\text { Responsible } \\
\text { decision-making } \dagger\end{array}$ \\
\hline
\end{tabular}

$A=$ first digit corresponds to the module and the second digit corresponds to the activity.

${ }^{*}$ Competence of Mayer and Salovey's model. ${ }^{33}$

†Basic competence proposed by CASEL.

CASEL, Collaborative for Academic, Social, and Emotional Learning.

which can be downloaded and played in mobile devices, and (b) funny elements to design and build a city on E-MOOD. The dynamics of the game are self-paced and self-instructive, facilitating the motivation and engagement of adolescents. Participants who do not complete $75 \%$ of the activities will be excluded from the study.

\section{Sample size}

According to the National Statistics Institute, ${ }^{36}$ the population of adolescents (10-19years) in Spain is 4912519. By choosing a $95 \%$ confidence level and a $5 \%$ margin of error, the representative sample size would be 385 participants. Participants will be randomly assigned to the control group and the experimental group using a computer-generated random numbers. The allocation sequence will be computer generated using a purposebuilt application.

\section{Outcomes}

The assessment of adolescents will involve emotional, personal, social, psychopathological and well-being areas. All instruments will be completed by the participants in baseline (T1), post-treatment (T2) and follow-up (T3).

\section{Primary outcomes}

Emotional competences will be assessed by two instruments. First, the Spanish version of the Trait Meta-Mood Scale$24^{37} 38$ has 24 items divided into three factors (attention, clarity and emotional repair) with a 5-point Likert scale. The psychometric properties of the instrument were adequate in Spanish adolescent samples $(\alpha=0.83$ in the three dimensions). ${ }^{39}$ Second, the Emotional Skills and Competence Questionnaire ${ }^{40}$ consists of 21 items divided into three scales (perception/understanding; labelling/expression; management/regulation), answered on a 6-point Likert scale. The questionnaire has shown good reliability in Spanish adolescent samples $(\alpha=(0.78$ to 0.91$)) .^{41}$

Subjective well-being will be assessed by two indicators. First, the Satisfaction With Life Scale ${ }^{42} 43$ assesses the cognitive dimension of well-being, that is, how satisfied people are with their lives, and is composed of five items with a 5-point Likert scale. Its internal consistency with Spanish adolescents was adequate (McDonald's $\Omega$ $=0.85) .{ }^{43}$ Second, the Scale of Positive and Negative Experiences ${ }^{4445}$ assesses the emotional dimension of well-being 
by the frequency of positive and negative feelings during the past 4 weeks. It consists of 12 items divided into two scales (positive and negative feelings) with a 7-point Likert scale, and it has shown good reliability in Spanish adolescent samples $(\alpha=(0.84$ to 0.92$)){ }^{45}$

\section{Secondary outcomes}

Self-esteem. The Rosenberg Self-Esteem Scale ${ }^{46}$ assesses the global attitude that adolescents have about themselves. It consists of 10 items scored with a 4-point Likert scale and has shown adequate psychometric properties with Spanish adolescents $(\alpha=0.87){ }^{47}$

General self-efficacy. General Self-Efficacy Scale ${ }^{48} 49$ assesses a stable feeling of personal competence to deal with a wide range of stressful situations. It is composed of 10 items answered on a 10-point Likert scale. The reliability in Spanish adolescent samples has shown adequate $(\alpha=0.89){ }^{49}$

Personality. The Mini-IPIP Scale positively worded Spanish version ${ }^{50}{ }^{51}$ consists of 20 items answered on a 5 -point scale and five dimensions: extraversion, agreeableness, conscientiousness, neuroticism and openness. The reliability of the factors in Spanish samples has shown adequate $($ composite reliability $=(0.87$ to 0.94$)) .^{50}$

Social and personal responsibility. The Spanish version of the Personal and Social Responsibility Questionnaire ${ }^{52} 53$ is composed of 14 items divided into two factors (social and personal responsibility), answered on a 6-point Likert scale, with adequate psychometric properties $(\alpha=(0.79$ to $0.80))^{53}$

School social climate. School Social Climate Questionnaire $^{5455}$ consists of 14 items with a 5-point Likert scale grouped in two factors (social climate relative to the school and relative to the teaching staff). The reliability of the factors in Spanish adolescent population has shown adequate $(\alpha=(0.72$ to 0.77$)) .^{54}$

Somatic complaints. The Somatic Complaint List ${ }^{756}$ is comprised of 11 items, answered using a 3-point Likert scale, and has shown adequate psychometric properties $(\alpha=0.80){ }^{57}$

Depression, anxiety and stress. The Depression, Anxiety, and Stress Scale ${ }^{585}$ assesses the affective symptoms during the previous week and is composed of 21 items divided into three scales (depression, anxiety and stress) with a 4-point Likert scale. Previous studies indicated adequate psychometric properties in Spanish samples $(\alpha=(0.73$ to $0.81)){ }^{60}$

Emotional and behavioural difficulties. The Strengths and Difficulties Questionnaire ${ }^{61} 62$ is composed of 25 items distributed on five subscales (emotional symptoms, behaviour problems, peer problems, hyperactivity and prosocial behaviour) with a 3-point Likert scale and has adequate psychometric properties in Spanish adolescents $(\alpha=(0.72$ to 0.87$)){ }^{47}$

Suicidal behaviour. The Adolescent Suicidal Behavior Assessment Scale $^{63}$ consists of 16 dichotomic items, 3 subscales (ideation, communication and act/planning) and a general factor. The reliability of the scale was adequate in Spanish adolescent samples $(\Omega$ coefficient $=(0.84$ to 0.94$)){ }^{63}$

Subjective happiness. The Spanish version of Subjective Happiness $\mathrm{Scale}^{6465}$ is a 4 -item Likert-type scale that requests the participant to self-rate or compare with others, and has shown an adequate reliability $(\alpha=0.81) .{ }^{64}$

\section{Data analysis}

Several statistical analyses will be used in order to determine the effectiveness of emoTIC. First, multivariate analysis of variance will be carried out to identify possible differences at $\mathrm{T} 1$ between the experimental group and the control group; and multivariate analysis of covariance will be performed to identify changes at $\mathrm{T} 2$, controlling for T1 scores (covariable). Second, the impact of the intervention programme will be analysed using multiple hierarchical regression analyses. The dependent variables will be the change between $\mathrm{T} 1$ and T2 in the outcome variables. Third, the reliable change index and $\mathrm{X}^{2}$ tests will be calculated. Fourth, the moderating effects of demographic variables will be tested. The experimental condition will be the independent variable and the changes from $\mathrm{T} 1$ to $\mathrm{T} 2$ will be the dependent variables. Fifth, structural equation models will be explored in order to analyse complex relations between variables. Finally, qualitative comparative analysis (QCA) will be used in order to complete the results obtained by the linear models. The statistical analysis will be done by means of the statistical packages SPSS (V.23), the PROCESS Macro for SPSS, Mplus (V.6.12) and Fs/QCA (V.3.0). All data will be entered electronically. Participant files will be stored in a secure and accessible manner for a period of 10 years after completion of the study.

\section{ETHICS AND DISSEMINATION}

The study has been approved by the Ethics Commission of the University of Valencia (H152865096049) and will comply with the data protection law (Organic Law 15/1999 on the Protection of Personal Data). A purposebuilt application will generate random codes for each student. Since adolescents under 18 years will participate, informed consent will be requested from them and their parents or legal guardians. The data will be analysed in order to determine the effectiveness of the programme and the results will be disseminated across the scientific community in different high-impact, peer-reviewed scientific journals. The results obtained in this study will be used for research and scientific publication purposes only, will be stored in databases and may be shared with other research groups, but will not be sold to third parties under any circumstances. Important protocol modifications will be reported to relevant parties (investigators, trial participants, trial registries, journals). 


\section{DISCUSSION}

The present project aims to design a serious game called emoTIC and analyse its effectiveness to develop emotional competences, well-being, mental health and personal strengths. Triangulation of the data will be performed using multivariate analysis of variance, multiple regression analysis and reliable change index to determine the effectiveness of emoTIC. The anticipated results of this study imply to provide a motivational tool that positively impacts adolescents' mental health and well-being. Using technology in the implementation of socioemotional programmes could be the first step towards developing and promoting interest in emotional education in adolescents. Despite the strengths of the study, it will have limitations. First, family is not included in the intervention. Second, incidental school sampling could make it difficult to generalise the results of the programme.

\section{CONCLUSION}

Working on emotional competences and personal strengths may contribute to enhance mental health and well-being in adolescence. This project will provide relevant knowledge for both the theoretical and the practical fields. On a theoretical level, the data collected will help to expand knowledge in the field of emotional education, specifically in the development of effective programmes and the related variables that can improve emotional intelligence. On a practical level, it will offer a tool for learning emotional competences that may be applied in the academic, family or social environment.

Contributors UDIB — conceptualisation, methodology and writing (original draft). SP-Z - conceptualisation and writing (original draft). EM-conceptualisation and writing (review and editing). J-AG-G-funding acquisition, project administration and writing (review and editing). IM-C—-funding acquisition, project administration and writing (review and editing).

Funding This research was supported by grants from the Spanish Ministry of Science, Innovation and Universities (PSI2017-84005-R), the State Agency of Research and the European Regional Development Fund (FEDER) from the European Union; as well as a research fellowship granted by the Regional Government of Valencia and the European Social Fund (ACIF/2018/033).

Disclaimer The funders had no role in study design, data collection and analysis, decision to publish or preparation of the manuscript.

Competing interests None declared.

Patient and public involvement Patients and/or the public were involved in the design, or conduct, or reporting, or dissemination plans of this research. Refer to the Methods section for further details.

Patient consent for publication Not required.

Provenance and peer review Not commissioned; externally peer reviewed.

Open access This is an open access article distributed in accordance with the Creative Commons Attribution Non Commercial (CC BY-NC 4.0) license, which permits others to distribute, remix, adapt, build upon this work non-commercially, and license their derivative works on different terms, provided the original work is properly cited, appropriate credit is given, any changes made indicated, and the use is non-commercial. See: http://creativecommons.org/licenses/by-nc/4.0/.

\section{ORCID iD}

Inmaculada Montoya-Castilla http://orcid.org/0000-0003-2536-2019
REFERENCES

1 WHO. Adolescent mental health in the European region, 2018. Available: http://www.euro.who.int/_data/assets/pdf_file/0005/ 383891/adolescent-mh-fs-eng.pdf?ua=1

2 WHO. Suicide data, 2016. Available: https://www.who.int/mental_ health/prevention/suicide/suicideprevent/en/

3 WHO. Preventing suicide: global imperative, 2014. Available: https:// www.who.int/mental_health/suicide-prevention/world_report_2014/ en/

4 Sawyer SM, Afifi RA, Bearinger LH, et al. Adolescence: a foundation for future health. Lancet 2012;379:1630-40.

5 de la Barrera U, Schoeps K, Gil-Gómez J-A, et al. Predicting adolescent adjustment and well-being: the interplay between socioemotional and personal factors. Int $J$ Environ Res Public Health 2019;16:4650.

6 Cejudo J, López-Delgado ML, Losada L. Effectiveness of the videogame "Spock" for the improvement of the emotional intelligence on psychosocial adjustment in adolescents. Comput Human Behav 2019;101:380-6.

7 Górriz Plumed AB, Prado-Gascó VJ, Villanueva Badenes L, et al. Psychometric properties of the somatic complaints scale in Spanish children and adults. Psicothema 2015;27:269-76.

8 Schoeps K, Villanueva L, Prado-Gascó VJ, et al. Development of emotional skills in adolescents to prevent cyberbullying and improve subjective well-being. Front Psychol 2018;9:9.

9 Lea RG, Davis SK, Mahoney B, et al. Does emotional intelligence buffer the effects of acute stress? A systematic review. Front Psychol 2019;10:810.

10 Domínguez-García E, Fernández-Berrocal P. The association between emotional intelligence and suicidal behavior: a systematic review. Front Psychol 2018;9:2380.

11 Hodzic S, Scharfen J, Ripoll P, et al. How efficient are emotional intelligence trainings: a meta-analysis. Emot Rev 2018;10:138-48.

12 Viguer P, Cantero MJ, Bañuls R. Enhancing emotional intelligence at school: evaluation of the effectiveness of a two-year intervention program in Spanish pre-adolescents. Pers Individ Dif 2017;113:193-200.

13 Crenshaw DA. Therapeutic engagement of children and adolescents: play, symbol, drawing, and storytelling strategies. Jason Aronson, 2008.

14 Almeida F. Adoption of a serious game in the developing of emotional intelligence skills. Eur J Investig Health Psychol Educ 2019;10:30-43.

15 Paiva ACR, Flores NH, Barbosa AG, et al. iLearnTest - framework for educational games. Procedia Soc Behav Sci 2016;228:443-8.

16 Kreuze E, Jenkins C, Gregoski M, et al. Technology-enhanced suicide prevention interventions: a systematic review. J Telemed Telecare 2017;23:605-17.

17 Grist R, Croker A, Denne M, et al. Technology delivered interventions for depression and anxiety in children and adolescents: a systematic review and meta-analysis. Clin Child Fam Psychol Rev 2019;22:147-71.

18 Calear AL, Christensen H, Mackinnon A, et al. The YouthMood project: a cluster randomized controlled trial of an online cognitive behavioral program with adolescents. J Consult Clin Psychol 2009;77:1021-32.

19 Attwood M, Meadows S, Stallard P, et al. Universal and targeted computerised cognitive behavioural therapy (think, feel, do) for emotional health in schools: results from two exploratory studies. Child Adolesc Ment Health 2012;17:173-8.

20 Manicavasagar V, Horswood D, Burckhardt R, et al. Feasibility and effectiveness of a web-based positive psychology program for youth mental health: randomized controlled trial. J Med Internet Res 2014;16:e140.

21 Kenny R, Dooley B, Fitzgerald A. Feasibility of "CopeSmart": a telemental health app for adolescents. JMIR Ment Health 2015;2:e22.

22 Kenny R, Fitzgerald A, Segurado R, et al. Is there an app for that? A cluster randomised controlled trial of a mobile app-based mental health intervention. Health Informatics J 2020;26:1538-59.

23 Ros-Morente A, Cabello Cuenca E, Filella Guiu G. Analysis of the effects of two gamified emotional education software's in emotional and well-being variables in Spanish children and adolescents. Int. J. Emerg. Technol. Learn. 2018;13:148-59.

24 D'Amico A. The use of Technology in the promotion of Children's Emotional Intelligence: The multimedia program "Developing Emotional Intelligence.". Int J Emot Educ 2018;10:47-67.

25 Cejudo J, Losada L, Feltrero R. Promoting social and emotional learning and subjective well-being: impact of the "Aislados" intervention program in adolescents. Int J Environ Res Public Health 2020;17:609.

26 David OA, Cardoș RAI, Matu S. Is REThink therapeutic game effective in preventing emotional disorders in children and 
adolescents? Outcomes of a randomized clinical trial. Eur Child Adolesc Psychiatry 2019;28:111-22.

27 David OA, Cardoș RAI, Matu S. Changes in irrational beliefs are responsible for the efficacy of the REThink therapeutic game in preventing emotional disorders in children and adolescents: mechanisms of change analysis of a randomized clinical trial. Eur Child Adolesc Psychiatry 2019;28:307-18.

28 David OA, Predatu R, Maffei A. Rethink online video game for children and adolescents: effects on state anxiety and frontal alpha asymmetry. Int J Cogn Ther 2021;14:399-416.

29 David OA, Predatu R, Cardoș RAI. Effectiveness of the REThink therapeutic online video game in promoting mental health in children and adolescents. Internet Interv 2021;25:100391.

30 Chan A-W, Tetzlaff JM, Altman DG, et al. SPIRIT 2013 statement: defining standard protocol items for clinical trials. Ann Intern Med 2013;158:200-7.

31 de la Barrera U, Mónaco E, Postigo-Zegarra S, et al. EmoTIC: impact of a game-based social-emotional programme on adolescents. PLoS One 2021;16:e0250384.

32 De la Barrera U, Postigo Zegarra S, Tamarit A. Desarrollo de competencias socioemocionales mediante plataforma tecnológica (Programa emoTIC): Valoración de los beneficios del programa según los participantes [Development of socioemotional competencies through a technological platform (emoTIC Program): Assessment of the benefits of the program according to the participants]. Know Share Psychol 2020;1:241-55.

33 Mayer JD, Salovey P. What is emotional intelligence? In: Salovey P, Sluyter D, eds. Emotional development and emotional intelligence: implications for educators. New York, NY: Basic Books, 1997: 3-31.

34 Mayer JD, Caruso DR, Salovey P. The ability model of emotional intelligence: principles and updates. Emot Rev 2016;8:290-300.

35 Collaborative for Academic, Social, and Emotional Learning. SEL: what are the core competence areas and where are they promoted? Available: https://casel.org/sel-framework/ [Accessed 25 Mar 2020].

36 National Statistics Institute. Main series of population since 1998. Available: https://www.ine.es/jaxiPx/Tabla.htm?path=/t20/e245/p08/ I0/\&file=02002.px\&L=1 [Accessed 25 Mar 2020].

37 Fernández-Berrocal P, Extremera N, Ramos N. Validity and reliability of the Spanish modified version of the trait meta-mood scale. Psychol Rep 2004;94:751-5.

38 Pedrosa I, Suárez-Álvarez J, Lozano LM. Assessing perceived emotional intelligence in adolescents: new validity evidence of trait Meta-Mood Scale-24. J Psychoeduc Assess 2014;32:737-46.

39 Guerra-Bustamante J, León-del-Barco B, Yuste-Tosina R, et al. Emotional intelligence and psychological well-being in adolescents. Int J Environ Res Public Health 2019;16:1720-12.

40 Takšić V, Mohorić T, Duran M. Emotional skills and competence questionnaire (ESCQ) as a self-report measure of emotional intelligence. Horizons Psychol 2009;18:7-21.

41 Schoeps K, Tamarit A, Montoya-Castilla I. Factorial structure and validity of the emotional skills and competences questionnaire (ESCQ) in Spanish adolescents. Behav Psychol 2019;27:275-93.

42 Diener E, Emmons RA, Larsen RJ, et al. The satisfaction with life scale. J Pers Assess 1985;49:71-5.

43 Ortuño-Sierra J, Aritio-Solana R, Chocarro de Luis E, et al. Subjective well-being in adolescence: new psychometric evidences on the satisfaction with life scale. Eur J Dev Psychol 2019;16:236-44.

44 Diener E, Wirtz D, Tov W, et al. New well-being measures: short scales to assess flourishing and positive and negative feelings. Soc Indic Res 2010;97:143-56.

45 Prado-Gascó V, Romero-Reignier V, Mesa-Gresa P, et al. Subjective well-being in Spanish adolescents: psychometric properties of the scale of positive and negative experiences. Sustainability 2020;12:4011.
46 Rosenberg M. Society and the adolescent self-image. Princeton University Press, 1965.

47 de la Barrera U, Montoya-Castilla I, Pérez-Albéniz A, et al. Mental health difficulties related to suicidal behavior in adolescents: the moderating role of self-esteem. Arch Suicide Res 2020:1-15.

48 Baessler J, Schwarcer R. Evaluación de la autoeficacia: Adaptación española de la escala de Autoeficacia General [assessment of self-efficacy: Spanish adaptation of the general self-efficacy scale]. Ansiedad Estres 1996;2:1-8.

49 Espada JP, Gonzálvez MT, Orgilés M. Validation of the general self-efficacy scale with Spanish adolescents. Electron J Res Educ Psychol 2012;10:355-70.

50 Martínez-Molina A, Arias VB. Balanced and positively worded personality short-forms: Mini-IPIP validity and cross-cultural invariance. PeerJ 2018:2018:6:e5542.

51 Donnellan MB, Oswald FL, Baird BM, et al. The mini-IPIP scales: tiny-yet-effective measures of the big five factors of personality. Psychol Assess 2006;18:192-203.

52 Li W, Wright PM, Rukavina PB, et al. Measuring students' perceptions of personal and social responsibility and the relationship to intrinsic motivation in urban physical education. $J$ Teach Phys Educ 2008;27:167-78.

53 Escartí A, Gutiérrez M, Pascual C. Propiedades psicométricas de la versión española del Cuestionario de responsabilidad personal y social en contextos de educación física [Psychometric properties of the Spanish version of the personal and social responsibility questionnaire in physical education contexts]. Rev Psicol Deporte 2011;20:119-30.

54 Trianes MV, Blanca MJ, de la Morena L, et al. [A questionnaire to assess school social climate]. Psicothema 2006;18:272-7.

55 Rosenblatt JA, Furlong MJ. Assessing the reliability and validity of student self-reports of campus violence. $J$ Youth Adolesc 1997;26:187-202.

56 Rieffe C, Oosterveld P, Terwogt MM. An alexithymia questionnaire for children: factorial and concurrent validation results. Pers Individ Dif 2006;40:123-33.

57 Mónaco E, Schoeps K, Montoya-Castilla I. Attachment styles and well-being in adolescents: how does emotional development affect this relationship? Int J Environ Res Public Health 2019;16:2554.

58 Lovibond PF, Lovibond SH. The structure of negative emotional states: comparison of the depression anxiety stress scales (DASS) with the Beck depression and anxiety inventories. Behav Res Ther 1995;33:335-43.

59 Daza P, Novy DM, Stanley MA, et al. The depression anxiety stress scale-21: Spanish translation and validation with a Hispanic sample. J Psychopathol Behav Assess 2002;24:195-205.

60 Fonseca-Pedrero E, Paino M, Lemos-Giráldez S. Pshychometric properties of the depression, anxiety and stress Scales-21 (DASS-21) in Spanish college students. Ansiedad Estres 2010;16:215-26.

61 Goodman R. The strengths and difficulties questionnaire: a research note. J Child Psychol Psychiatry 1997;38:581-6.

62 Ortuño-Sierra J, Chocarro E, Fonseca-Pedrero E, et al. The assessment of emotional and behavioural problems: internal structure of the strengths and difficulties questionnaire. Int J Clin Health Psychol 2015;15:265-73.

63 Díez-Gómez A, Pérez-Albéniz A, Ortuño-Sierra J, et al. Sentia: an adolescent suicidal behavior assessment scale. Psicothema 2020;32:382-9.

64 Extremera N, Fernández-Berrocal P. The subjective happiness scale: translation and preliminary psychometric evaluation of a Spanish version. Soc Indic Res 2014:119:473-81.

65 Lyubomirsky S, Lepper HS. A measure of subjective happiness: preliminary reliability and construct validation. Soc Indic Res 1999:46:137-55 